\title{
QUEEN'S
UNIVERSITY
BELFAST
}

\section{Error-Driven Learning: A New Teaching Methodology for Improving the Learning Experience in Stem Education}

Reaño, C. (2021). Error-Driven Learning: A New Teaching Methodology for Improving the Learning Experience in Stem Education. In 13th International Conference on Education and New Learning Technologies (EDULEARN 2021) Proceedings (pp. 4254-4259). (International Conference on Education and New Learning Technologies: Proceedings). https://doi.org/10.21125/edulearn.2021.0901

Published in:

13th International Conference on Education and New Learning Technologies (EDULEARN 2021) Proceedings

\section{Document Version:}

Peer reviewed version

Queen's University Belfast - Research Portal:

Link to publication record in Queen's University Belfast Research Portal

Publisher rights

(C) 2021 IATED.

This work is made available online in accordance with the publisher's policies. Please refer to any applicable terms of use of the publisher.

\section{General rights}

Copyright for the publications made accessible via the Queen's University Belfast Research Portal is retained by the author(s) and / or other copyright owners and it is a condition of accessing these publications that users recognise and abide by the legal requirements associated with these rights.

Take down policy

The Research Portal is Queen's institutional repository that provides access to Queen's research output. Every effort has been made to ensure that content in the Research Portal does not infringe any person's rights, or applicable UK laws. If you discover content in the Research Portal that you believe breaches copyright or violates any law, please contact openaccess@qub.ac.uk. 


\title{
ERROR-DRIVEN LEARNING: A NEW TEACHING METHODOLOGY FOR IMPROVING THE LEARNING EXPERIENCE IN STEM EDUCATION
}

\author{
Carlos Reaño ${ }^{1}$ \\ ${ }^{1}$ Queen's University Belfast (UNITED KINGDOM)
}

\begin{abstract}
The most extended and popular teaching methodology is probably that of direct instruction. In this methodology, the teacher is in the centre of the model and directly instructs the students. The knowledge is transferred from the teacher to the students through lectures, following a one-way communication only. Students are therefore passive agents who merely receive the information. This allows for little interaction between the teacher and the students, and does not encourage student engagement in learning.

This paper presents "Error-Driven Learning", a new teaching methodology envisaged for improving the student learning experience, particularly in science, technology, engineering, and mathematics (STEM) academic disciplines. In this new methodology, not only the teacher but also the students participate in the learning process. There is a two-way communication between the teacher and the students. For achieving that, the teacher deliberately introduces errors in lectures and practical exercises with the purpose of encouraging the students to detect and correct those errors. This significantly increases the interactivity and participation in the lectures. The students are more attentive and engaged, which ultimately translates into a better learning experience. An undergraduate course in Computer Science is employed as a use case for evaluating the proposed approach.
\end{abstract}

Keywords: Teaching methodologies, STEM, student engagement, learning innovations.

\section{INTRODUCTION}

Among the existing different teaching methodologies [1], probably the most extended and popular one is that of direct instruction [2]. As shown in Fig. 1, in this methodology the teacher is in the centre of the model and directly instructs the students. The knowledge is transferred from the teacher to the students through lectures, following a one-way communication only. Students are therefore passive agents who merely receive the information. This allows for little interaction between the teacher and the students, and does not encourage student engagement in learning.

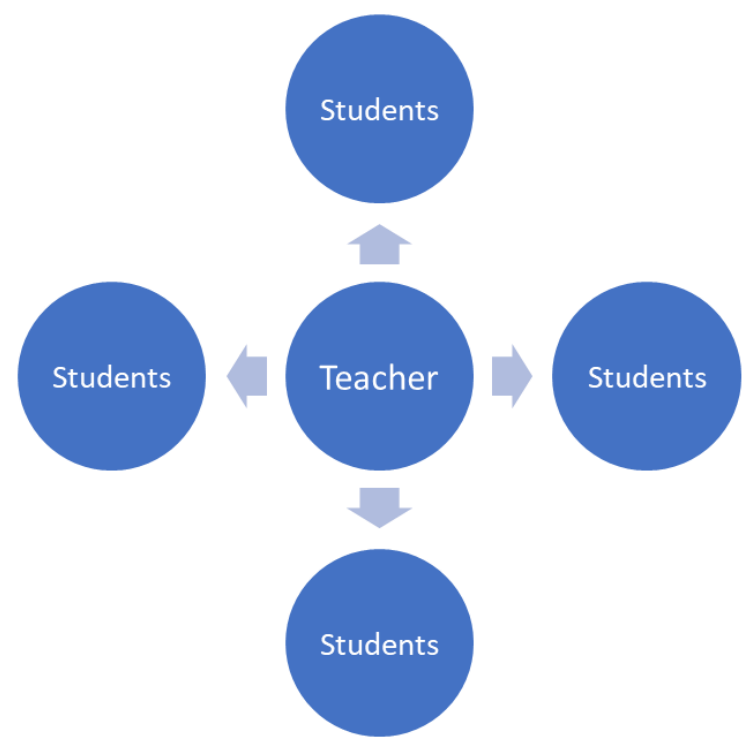

Figure 1. Direct instruction where the teacher is the centre of the model. 
There exist however other approaches in which the students are at the centre of the model, such as inquiry-based learning [3] or game-based learning [4]. As shown in Fig. 2, in these models the students are in the centre of the model. The knowledge is gained by the students through the teacher, the teaching material and the feedback received from assignments and assessments. Students are therefore active agents who interact with the available resources to learn. This allows for high interaction between the teacher and the students, and encourages student engagement in learning.

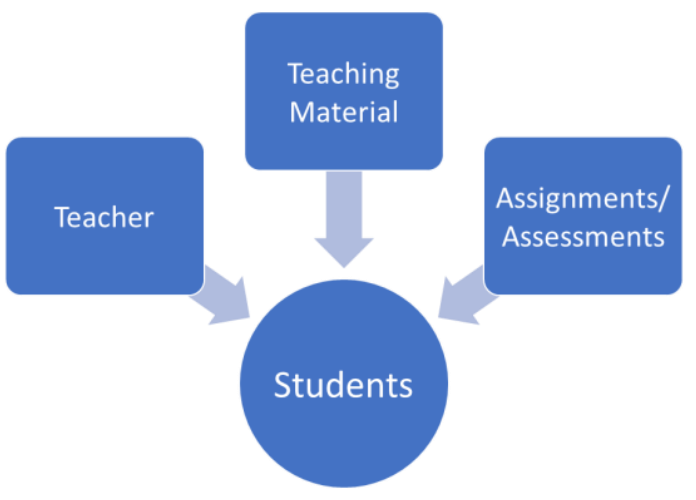

Figure 2. Non-direct instruction where the student is the centre of the model.

Inspired by this kind of teaching methods, in this paper we present "Error-Driven Learning", a new teaching methodology envisaged for improving the student learning experience, particularly in science, technology, engineering, and mathematics (STEM) academic disciplines. In this new methodology, not only the teacher but also the students participate in the learning process. There is a two-way communication between the teacher and the students. For achieving that, the teacher deliberately introduces errors in lectures and practical exercises with the purpose of encouraging the students to detect and correct those errors. This significantly increases the interactivity and participation in the lectures. The students are more attentive and engaged, which ultimately translates into a better learning experience. An undergraduate course in Computer Science is employed as a use case for evaluating the proposed approach.

The rest of the paper is organized as follows. In Section 2 we present in more detail the methodology proposed. Next, in Section 3, we show the results of applying that methodology in a real scenario. Finally, we conclude the paper in Section 4.

\section{METHODOLOGY}

As commented, we propose a non-direct instruction methodology where the students are at the centre of the model (see Fig. 2). By doing this, we create a two-way communication between the teacher and the students. For achieving that, the teacher deliberately introduces errors in lectures and practical exercises. The rationale behind this is that the students will follow the lectures and practical exercises more attentively to detect and correct those errors with the help of the teacher during the lecture time. The final goal is to increase the interactivity and participation of the students in the lectures and practical exercises. It is expected that following this methodology the students are more motivated and engaged, which ultimately translates into a better learning experience.

An undergraduate course in Computer Science [5] is employed as a use case for evaluating the proposed approach. In particular, the module used was "Advanced Computer Architecture" [6], which is one of the optional courses at Stage 4, the last stage of the degree. We will also use material from this course to explain the proposed approach. Fig. 3 shows a sample exercise proposed to the students during that course. 
Exercise. Consider we want to improve the performance of a program. What will be the overall speedup obtained by improving the arithmetic logic unit (ALU), which is used $95 \%$ of time, by $10 \%$ ?

Figure 3. Exercise proposed.

In this exercise, the students are expected to use the well-known Amdhal's Law [7] to solve it. Amdahl's Law states that if a program optimisation speeds up a fraction $f$ of the program by a factor of $s$, the predicted speedup is given by Equation 1.

$$
\text { Speedup }=\frac{1}{1-f+\frac{f}{s}}
$$

Equation 1. Amdhal's Law.

A common mistake done by students when applying Equation 1 to solve the exercise in Fig. 3 is to use 10 for the value of $s$. Following our methodology, we will in first instance solve the exercise for the students precisely doing that, as shown in Fig. 4.

$$
\text { Speedup }=\frac{1}{1-f+\frac{f}{s}}=\frac{1}{1-0.95+\frac{0.95}{10}}=6.897
$$

Figure 4. Incorrect solution shown to students initially.

At this point, it is expected that some students realise the mistake and ask the teacher for further explanation on why $s$ is equal to 10 , instead of calculating the value of $s$ using the formula studied in previous lectures, which is show in Figure 5.

$$
10 \% \text { speedup } \rightarrow s=\frac{1}{1-10 \%}=\frac{1}{1-0.1}=1.1111111
$$

Figure 5. Correct way for calculating the value of $s$.

If that does not happen and the students do not see the mistake, the teacher should challenge them and make that they notice the error. Once that happens, the teacher will provide the correct answer, shown in Fig. 6, following the corrections made by the students.

$$
\text { Speedup }=\frac{1}{1-f+\frac{f}{s}}=\frac{1}{1-0.95+\frac{0.95}{1.1111111}}=1.105
$$

Figure 6. Correct solution shown to students in the end. 
Although this methodology could be randomly used during the course, we have devised it to be applied in common mistakes or important parts, and not as a general rule for any exercise. Therefore, our advice would be not to overuse it.

\section{RESULTS}

We applied the methodology explained in the previous section during the first three weeks of the aforementioned undergraduate course in Computer Science. After that period, we conducted the survey shown in Fig. 7. In our case, we mainly applied the methodology when manually solving practical exercises using a document camera similar to the one shown in Fig. 8. For that reason, in the survey we also ask to the students for feedback on the use of this tool for solving the exercises.

\section{Teaching Methods Survey - Weeks 1, 2 and 3}

During the first three weeks we have used different teaching techniques and methods. This survey will allow as to gather some feedback from you. There is also some space for suggestions in this regard. Submissions are anonymous. Please, do the best you can to answer honestly.

\section{Question 1}

Do you like the use of the document camera for additional explanations and exercises?
O True
O False

\section{Question 2}

In some of the exercises we do mistakes on purpose (typical mistakes students do). The intention is making the students pay more attention and ask more questions. The correct solutions are available some days after the lecture.

O I like this method. Seeing typical mistakes raises a lot of questions which in the end makes me better understanding the exercise.

O I do not like this method. It confuses me. I would prefer seeing the correct solution from the beginning.

\section{Question 3}

Please, let us know suggestions and comments regarding the teaching methods used during weeks 1,2 and 3 (things you liked, things you did not like, things you think could be useful...).

Figure 7. Survey conducted after testing the methodology proposed.

The survey in Fig. 7 was conducted among the approximately 60 students of the aforementioned course. From them, only 15 students submitted feedback. Although we would have desired more participation to draw more representative conclusions, we think that having feedback from $25 \%$ of the students of the course could still be useful and provide helpful comments. Table 1 presents the results for Question 1 and Question 2 of the survey. Results for Question 3 are presented in Table 2. 


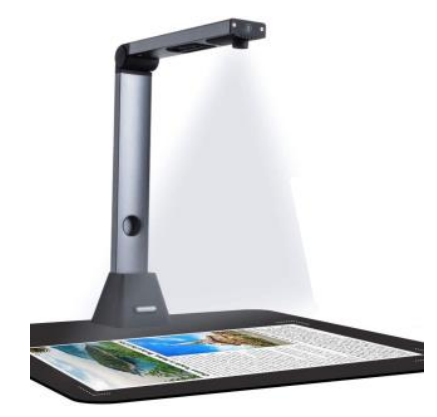

Figure 8. iCODIS Document Camera X3 [8].

Table 1. Survey results (Question 1 and Question 2).

\begin{tabular}{l|c|c|}
\hline \hline & Question 1 & Question 2 \\
\hline $\begin{array}{l}\text { True / I like this } \\
\text { methodology }\end{array}$ & $100 \%$ & $33 \%$ \\
\hline $\begin{array}{l}\text { False / I do not like } \\
\text { this methodology }\end{array}$ & $0 \%$ & $66 \%$ \\
\hline
\end{tabular}

As we can see in Table 1, all the students participating in the survey liked the use of the document camera for additional explanations and for manually solving the exercises. However, regarding the use of the propose methodology, which in this case consisted in deliberately doing mistakes when showing the solutions of some of those exercises, that was not the case. Thus, only $33 \%$ of the students participating in the survey liked this methodology, whereas $66 \%$ did not liked it. As commented, the rationale behind this methodology was making the students pay more attention and ask more questions. The correct solutions were made available after the lecture.

According to the results of Question 2, it seems that the methodology proposed was not satisfactory from the students point of view. To better understand the reasons behind this, we analysed the different feedback obtained from students in Question 3, which is shown in Table 2. In the last column of the table, we have classified the feedback in positive, negative or neutral, depending on whether the feedback refers to positive, negative or neutral aspects of the teaching methods used. In summary, two of the comments were classified as positive comments, two as neutral ones, three as negative ones, and the remainder of students participating in the survey did not provide any comment to support their choices in the survey.

With respect to the two positive comments, these do not provide any direct feedback regarding the teaching methodology analysed in this paper. From the two neutral comments, however, one of them refers to the methodology as follows: "Good idea to explain typical mistakes. Though it might be best to mention whether they are deliberate mistakes during the lecture", Student 15. Therefore, one way of improving this methodology could be making available the correct solutions during the lecture, instead of doing that after the lecture, as we have done in this course.

From the three negative questions, one of them provides the following feedback regarding the teaching methodology analysed in this paper: "Regarding Question 2, I think it would be preferable to highlight any common mistakes rather than including them without explanation", Student 9. In this case, the student clearly advocates for directly explaining the typical mistakes, instead of the approach used of allowing students to notice mistakes.

Considering the feedback, in particular the two comments highlighted before, it seems that the major problem of the methodology proposed was "when" the correct solutions and mistakes were revealed to the students. From the students feedback, it seems that if this is done during the lecture, the methodology could provide better results and enhance the student learning. 
Table 2. Survey results (Question 3).

\begin{tabular}{|c|c|c|}
\hline & Question 3 & $\begin{array}{c}\text { Type of feedback } \\
\text { (positive/neutral/negative) }\end{array}$ \\
\hline Student 1 & $\begin{array}{l}\text { "I liked when the lecturer went } \\
\text { over practical questions and went } \\
\text { through the answers." }\end{array}$ & Positive \\
\hline Students 2-4 & No answer. & \\
\hline Student 5 & $\begin{array}{c}\text { "I found the content quite } \\
\text { interesting and I feel that the use } \\
\text { of worked exercises being shown } \\
\text { was very useful." }\end{array}$ & Positive \\
\hline Students 6-7 & No answer. & \\
\hline Student 8 & $\begin{array}{l}\text { "Lectures moved very fast and } \\
\text { were hard to follow. More } \\
\text { interaction with students and } \\
\text { taking time to explain complicated } \\
\text { topics would help. Lectures felt } \\
\text { very rushed to get finished with } \\
\text { the slides so that we could move } \\
\text { on to do exercises, but without } \\
\text { grasping the knowledge from the } \\
\text { slides the exercises weren't as } \\
\text { effective as they could have } \\
\text { been." }\end{array}$ & Negative \\
\hline Student 9 & $\begin{array}{c}\text { "Regarding Question 2, I think it } \\
\text { would be preferable to highlight } \\
\text { any common mistakes rather than } \\
\text { including them without } \\
\text { explanation." }\end{array}$ & Negative \\
\hline Students $10-12$ & No answer. & \\
\hline Student 13 & $\begin{array}{l}\text { "More examples for some of the } \\
\text { problems would be helpful." }\end{array}$ & Neutral \\
\hline Student 14 & $\begin{array}{c}\text { "Still cannot see all of the } \\
\text { document viewer solutions in } \\
\text { canvas". These would be good to } \\
\text { be uploaded as I could then } \\
\text { concentrate more on the example } \\
\text { instead of trying to copy it. } \\
\text { Thanks" }\end{array}$ & Negative \\
\hline Student 15 & $\begin{array}{c}\text { "Good idea to explain typical } \\
\text { mistakes. Though it might be best } \\
\text { to mention whether they are } \\
\text { deliberate mistakes during the } \\
\text { lecture." }\end{array}$ & Neutral \\
\hline
\end{tabular}




\section{CONCLUSIONS}

In this paper we have presented "Error-Driven Learning", a new teaching methodology envisaged for improving the student learning experience, particularly in STEM academic disciplines. The idea behind this new methodology is that not only the teacher but also the students participate in the learning process. In particular, for achieving that, in this paper we have implemented the methodology as follows. The teacher deliberately introduced errors in lectures and practical exercises with the purpose of encouraging the students to detect and correct those errors. By doing that, we initially expected increasing the interactivity and participation in the lectures. An undergraduate course in Computer Science was employed as a use case for evaluating the proposed approach.

The results show that, according to the feedback provided by the students, further adjustments and experimentation must be done with the methodology for achieving the desired results. In this regard, the students concerns were mainly related to the fact that correct results were available after the lecture rather than during the lecture. As future work, we plan to repeat the experiments carried out in this paper but modifying the methodology to show the correct results and explicitly highlight common mistakes during the lecture. With these modifications, we expect to obtain more positive feedback from the students and enhance the learning experience.

\section{ACKNOWLEDGEMENTS}

I would like to thank the School of Electronics, Electrical Engineering and Computer Science from Queen's University Belfast, United Kingdom. In particular, to the colleagues who helped me gather all the information and carry out the experiments, contributing in great measure to the completion of this work. It would not have been possible without their cooperation, and I wish to express my appreciation to all of them for their assistance and support. In addition, I would also like to extend my gratitude to the students who provided their valuable feedback. Their comments were really useful and helpful. Thanks to their feedback, we hope to improve the current work in the future.

\section{REFERENCES}

[1] 2U Inc., "Teaching Methods", Teach.com, accessed 1 May, 2021. Retrieved from https://teach.com/what/teachers-know/teaching-methods/

[2] $2 U$ Inc., "Teacher-Centered Methods of Instruction - Direct Instruction", Teach.com, accessed 1 May, 2021. Retrieved from https://teach.com/what/teachers-know/teachingmethods/\#teachercentered

[3] 2U Inc., "Student-Centered Methods of Instruction - Inquiry-based Learning", Teach.com, accessed 1 May, 2021. Retrieved from https://teach.com/what/teachers-know/teachingmethods/\#studentcentered

[4] $2 U$ Inc., "Student-Centered Methods of Instruction - Game-based Learning", Teach.com, accessed 1 May, 2021. Retrieved from https://teach.com/what/teachers-know/teachingmethods/\#studentcentered

[5] Queen's University Belfast, "BSc | Undergraduate | Computer Science", accessed 1 May, 2021. Retrieved from https://www.qub.ac.uk/courses/undergraduate/computer-science-professionalexperience-bsc-g400

[6] Queen's University Belfast, "CSC 3058 - Advanced Computer Architecture", accessed 1 May, 2021. Retrieved from https://qsiscat.qub.ac.uk/

[7] J. L. Gustafson, "Amdahl's Law" in Encyclopedia of Parallel Computing (Padua D. eds.). Boston, MA: Springer, 2011. Retrieved from https://doi.org/10.1007/978-0-387-09766-4_77

[8] Hong Kong Codis Electronic Co.Itd, iCODIS Document Camera X3, accessed 1 May, 2021. Retrieved from https://www.projecticodis.com/products/megascan-pro-x3-ocr-a3-pdf-documentcamera-scanner

[9] Instructure Inc., "Canvas Learning Management Platform", accessed 1 May, 2021. Retrieved from https://www.instructure.com 